\title{
Aesthetic Facial Correction of Cleidocranial Dysplasia
}

\author{
So-Min Hwang, \\ Beom Park, \\ Min-Kyu Hwang, \\ Min-Wook Kim, \\ Jong-Seo Lee \\ Aesthetic, Plastic and Reconstructive Surgery \\ Center, Good Moonhwa Hospital, Busan, \\ Korea
}

No potential conflict of interest relevant to this article was reported.

\begin{abstract}
We report two cases of cleidocranial dysplasia, which was managed without significant craniofacial osteotomy. A mother and daughter, both of normal intelligence, presented with central forehead depression, mid-face hypoplasia, and blepharoptosis. The fact that they have an identically deformed face implied a genetic basis. In both patients, radiologic evaluation revealed the underdeveloped maxilla, persistent fontanelle opening, and cleidal aplasia. Clinical findings and radiologic studies were consistent with the diagnosis of cleidocranial dysplasia. Both patients underwent forehead plasty via bicoronal approach, augmentation rhinoplasty using tip plasty, and epicanthoplasty. In addition, the mother underwent malar augmentation using Medpor implantation and reduction genioplasty. The patients did not experience any postoperative complication and remained satisfied with the operation at 6-year follow-up.
\end{abstract}

Keywords: Cleidocranial dysplasia / Inborn genetic diseases / Maxilla / Clavicle

\section{INTRODUCTION}

Cleidocranial dysplasia (CCD), also known as Marie and Sainton Disease, Scheuthauer Marie-Sainton Syndrome, and mutational dysostosis, is an autosomal dominant genetic bone disease involving the facial bones, the skull, and the collarbone. CCD is characterized by brachycephaly, hypertelorism, prominent orbital ridges, the inferior margin reduced to the small maxillae, and relative mandibular prognathism [1-3]. Patients with CCD can have several supernumerary teeth, with eruption lag or disorder of permanent teeth. The condition also affects the spine and appendicular skeleton by endochondral ossification. Cleidal hypoplasia or aplasia may lead to hyper-approximation of the shoulders [3]. We present aesthetic management of mother-daughter case of CCD (Table 1).

\section{Correspondence: So-Min Hwang}

Aesthetic, Plastic and Reconstructive Surgery Center, Good Moonhwa Hospital, 119 Beomil-ro, Dong-gu, Busan 48735, Korea

E-mail: sominhwang@hanmail.net

Received August 26, 2015 / Revised October 12, 2015 / Accepted December 3, 2015

\section{CASE REPORTS}

\section{Case 1}

A 20-year-old woman with several unerupted teeth presented to the department of pedodontia at our institution. The patient was of average build and short height, but did not have any history of developmental delay. Physical examination revealed a brachycephalic head and facial asymmetry, fronto-parietal bossing, prominent orbital ridges, moderate hypertelorism in the large ala-base, and a depressed nasal bridge (Fig. 1). In addition, she had hyper-

Table 1. Facial abnormalities and corrective operation in two cases of cleidocranial dysplasia

\begin{tabular}{|c|c|c|c|}
\hline Facial abnormalities & Case 1 & Case 2 & Corrective operation \\
\hline $\begin{array}{l}\text { Bossing of the } \\
\text { forehead }\end{array}$ & $\mathrm{O}$ & $\mathrm{O}$ & $\begin{array}{l}\text { Forehead plasty using bone } \\
\text { cement }\end{array}$ \\
\hline Hypertelorism & $\mathrm{O}$ & - & Epicanthoplasty \\
\hline Low nasal bridge & $\mathrm{O}$ & - & Augmentation rhinoplasty \\
\hline Midface hypoplasia & - & $\mathrm{O}$ & $\begin{array}{l}\text { Malar and paranasal } \\
\text { augmentation using } \\
\text { Medpor }\end{array}$ \\
\hline $\begin{array}{l}\text { Mandibular } \\
\text { prognathism }\end{array}$ & $\mathrm{O}$ & $\mathrm{O}$ & Reduction genioplasty \\
\hline
\end{tabular}


mobility of the shoulders, which is a symptom characteristic of CCD and results from cleidal aplasia or hypoplasia (Fig. 2). Chest $\mathrm{X}$-ray was noticeable for the narrow thoracic cage with drooping ribs (Fig. 3). The patient also had short, thick fingers and nail hypoplasia. Examination of oral cavity revealed several deciduous teeth without any upper right permanent central incisor or lower permanent central incisor. The patient had moderate bilateral cross-bite and class III incisor relationship. Panoramic X-ray revealed a large number of unerupted permanent teeth, residual baby teeth, and several supernumerary impacted teeth (Fig. 4).

This patient underwent forehead plasty via bicoronal approach using bone cement (BonSource, Stryker Leibinger, Kalamazoo, MI, USA), augmentation rhinoplasty with tip plasty, and correction of blepharoptosis and epicanthoplasty (Fig. 5).

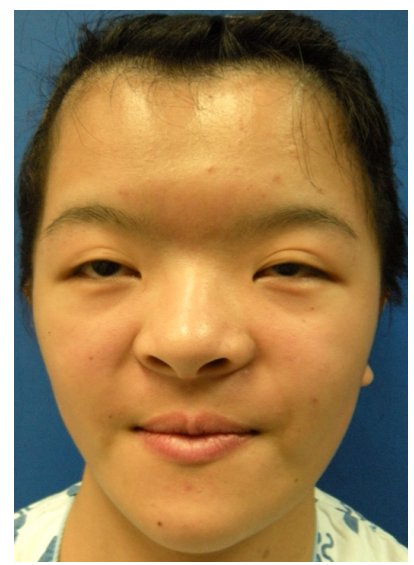

Fig. 1. Photograph of the daughter (Case 1) prior to operation. The patient's facial features are notable for frontoparietal bossing, prominent orbital ridges, mild hypertelorism, and depressed nasal bridge with broad alar base.

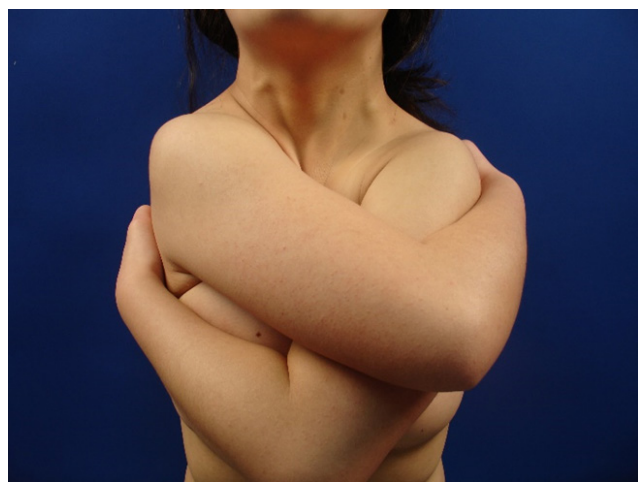

Fig. 2. The patient demonstrates shoulder joint hypermobility, which is a common clinical finding in cleidocranial dysplasia.

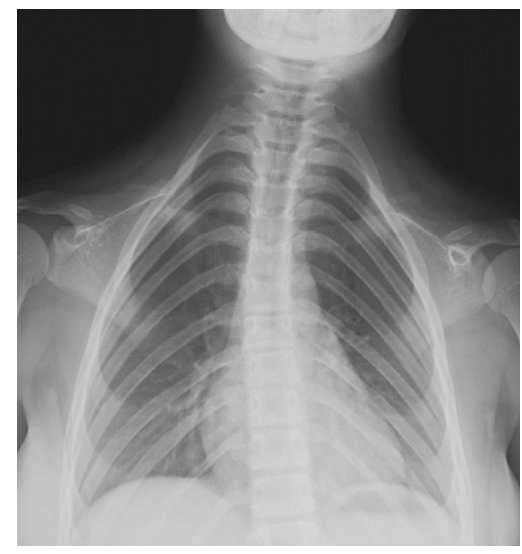

Fig. 3. Chest X-ray of the daughter patient shows narrow thorax with drooping ribs.

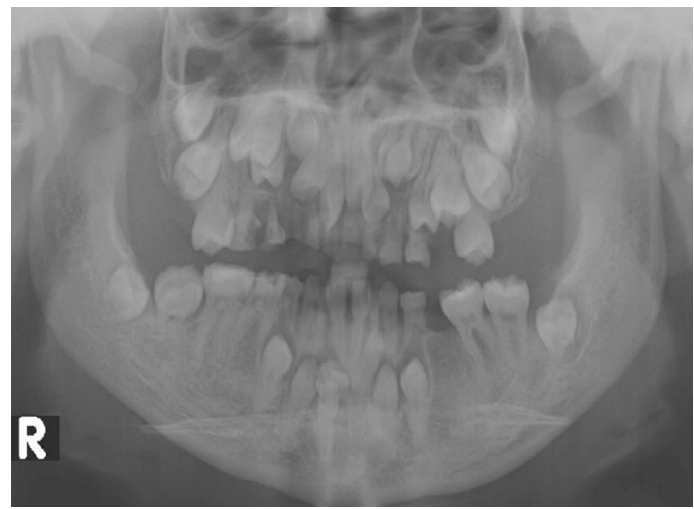

Fig. 4. Panoramic X-ray of dentition in Case 1. The deciduous dentition is retained, and much of the permanent dentition remains unerupted.

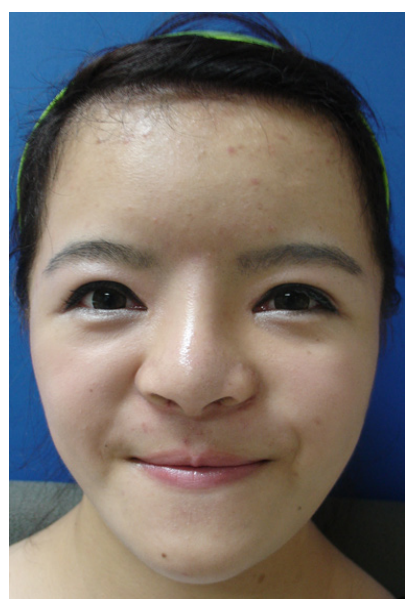

Fig. 5. The daughter patient at 6 months after operation. The patient underwent forehead plasty using bone cement, augmentation rhinoplasty with tip-plasty, alar reduction, correction of blepharoptosis, and epicanthoplasty. 


\section{Case 2}

The second patient was Case 1 patient's mother. She was of small stature and average build. This case was less severe than Case 1. Frontal bossing was observed in this case (Fig. 6). The panoramic X-ray showed impacted permanent teeth and absence of several permanent teeth (Fig. 7). This patient underwent forehead plasty via bicoronal approach using bone cement, malar and paranasal augmentation using Medpor implants (Stryker Leibinger), and reduction genioplasty (Fig. 8).

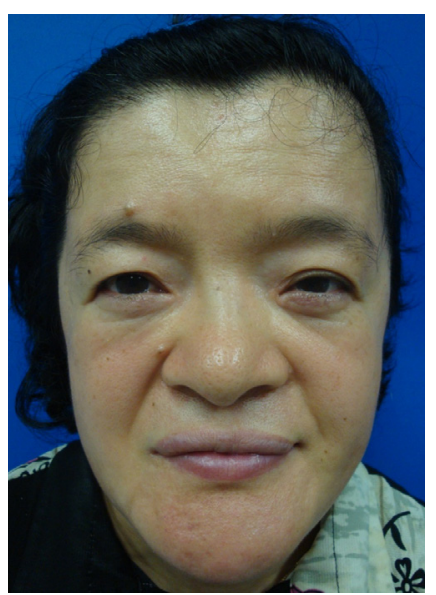

Fig. 6. Preoperative photograph of the mother patient (Case 2). Facial feature is significant for frontal bossing and protruding chin.

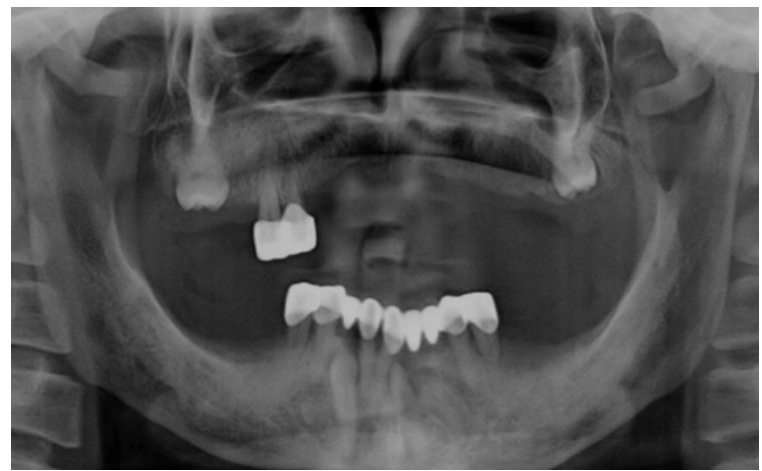

Fig. 7. Panoramic X-ray of dentition in Case 2. Permanent dentition remains unerupted in the mother as well.

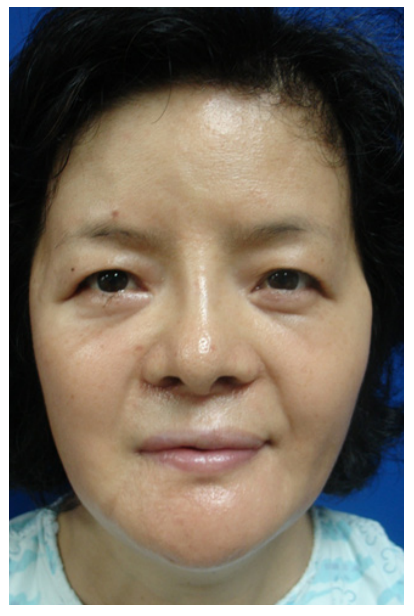

Fig. 8. Postoperative photograph at 2 months after the operation. The patient had underwent forehead plasty using bone cement, malar augmentation, paranasal augmentation, and reduction genioplasty.

\section{DISCUSSION}

CCD is a hereditary congenital disorder characterized by skeletal abnormalities such as prominent frontal and parietal bones, hypertelorism, underdeveloped maxilla and zygomatic bones, supernumerary unerupted teeth, or cleidal aplasia/hypoplasia [4]. The condition was first reported by Meckel in 1760 [5]. Human osteoblast-specific, runt-related transcription factor 2 (RUNX2) genes, core binding factor A1 (CBFA1), AML3, and OSF2 have recently been identified as CCDcausing genes. Mutations in these genes are passed to offspring in the autosomal dominant pattern, but novel mutations represent $20 \%$ to $40 \%$ of all patients with CCD $[6,7]$.

In most patients, CCD only affects membranous bones, but the condition has been reported to affect endochondral bones as well [6]. Mandibular deformities are reported to occurred in 95\% of cases. In general, mandibular prognathism occurs due to the normally developed mandible and the underdeveloped premaxilla [8].

A simple procedure using epicanthoplasty could be performed for an aesthetic purpose in these cases with the orbits not being clearly asymmetric. The malar and paranasal areas were augmented using Medpor implants, which was effective in improving the overall projection of the midface. Reduction genioplasty was further helpful in treating the relative mandibular prognathism caused by midface retraction.

The literature on CCD has focused on the genetic aspect and on the 
correction of dental and cleidal deformities. Few studies have reported using bone cement to correct forehead bossing in CCD patients, and there have been only a few cases on the correction of facial deformities, such as hypertelorism, a low nasal bridge, depressed midface, and mandibular prognathism.

We are willing to share our clinical experiences in the congenital characteristics of familial CCD. We also try to give aesthetically satisfactory effects through a relatively less invasive procedure than cranioplasties found in literature.

\section{REFERENCES}

1. Mehta DN, Vachhani RV, Patel MB. Cleidocranial dysplasia: a report of two cases. J Indian Soc Pedod Prev Dent 2011;29:251-4.
2. Cohen MM Jr. Biology of RUNX2 and cleidocranial dysplasia. J Craniofac Surg 2013;24:130-3.

3. Yoshida T, Kanegane H, Osato M, Yanagida M, Miyawaki T, Ito Y, et al. Functional analysis of RUNX2 mutations in cleidocranial dysplasia: novel insights into genotype-phenotype correlations. Blood Cells Mol Dis 2003;30:184-93.

4. Han K, Ham H, Kang J. An anthropometric analysis of cleidocranial dysostosis. J Korean Soc Plast Reconstr Surg 1994;21:121-34.

5. Siggers DC. Cleidocranial dysostosis. Dev Med Child Neurol 1975;17:522-4.

6. Fitchet SM. Cleidocranial dysostosis: hereditary and familial. J Bone Joint Surg 1929;11:838-66.

7. Rushton MA. An anomaly of cementum in cleidocranial dysostosis. Br Dent J 1956;100:81-3.

8. Jarvis JL, Keats TE. Cleidocranial dysostosis: a review of 40 new cases. Am J Roentgenol Radium Ther Nucl Med 1974;121:5-16. 